\title{
Investigations of aerosol impacts on hurricanes: virtual seeding flights
}

\author{
G. G. Carrio and W. R. Cotton \\ Department of Atmospheric Science, Colorado State University, Fort Collins, CO 80523, USA
}

Received: 19 July 2010 - Published in Atmos. Chem. Phys. Discuss.: 30 September 2010

Revised: 21 January 2011 - Accepted: 21 February 2011 - Published: 18 March 2011

\begin{abstract}
This paper examines the feasibility of mitigating the intensity of hurricanes by enhancing the $\mathrm{CCN}$ concentrations in the outer rainband region. Increasing $\mathrm{CCN}$ concentrations would cause a reduced collision and coalescence, resulting in more supercooled liquid water to be transported aloft which then freezes and enhances convection via enhanced latent heat of freezing. The intensified convection would condense more water ultimately enhancing precipitation in the outer rainbands. Enhanced evaporative cooling from the increased precipitation in the outer rainbands would produce stronger and more widespread areal cold pools which block the flow of energy into the storm core, ultimately inhibiting the intensification of the tropical cyclone.

We designed a series of multi-grid for which the time of the "virtual flights" as well as the aerosol release rates are varied. A code that simulates the flight of a plane is used to increase the $\mathrm{CCN}$ concentrations as an aircraft flies. Results show a significant sensitivity to both the seeding time and the aerosol release rates and support the aforementioned hypothesis.
\end{abstract}

\section{Introduction}

Many studies examined various possible mechanisms of convective intensification due to aerosol indirect effects. The invigoration of cloud growth from increased aerosol concentration slows the rate of conversion of cloud droplets into rain drops, so that more cloud water ascends to altitudes at which the temperature is below the freezing level (Khain et al., 2001, 2004, 2005; Lynn et al, 2005; Seifert and Beheng, 2006; van den Heever et al., 2006; van den Heever and

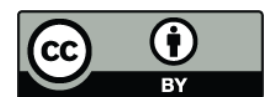

Correspondence to: G. G. Carrio (carrio@atmos.colostate.edu)
Cotton, 2007; Rosenfeld et al., 2008). The condensed water is likely to freeze and thereby releases greater amounts of latent heat. The delay in the formation of raindrop growth and ice alters the vertical profile of latent heat release and is sufficient to cause invigoration of cloud dynamics. This process has been modeled by Khain et al. (2004, 2005, 2008); Seifert and Beheng (2006); van den Heever et al. (2006); van den Heever and Cotton (2007); Carrió et al. (2010), and Carrió and Cotton (2011). Seifert and Beheng (2006) note, however, that if the convection is not intense enough to thrust condensate into supercooled altitude levels, then the updrafts can become water-loaded. As a result, precipitation and storm dynamics can be suppressed by increased CCN. Moreover, van den Heever and Cotton (2007) note that enhanced CCN can invigorate cumulus dynamics early during their development phase, but once low-level cold-pools are modified, the resultant behavior of the system is dependent upon secondary cloud growth, which, for the case they simulated, resulted in weakened convection and reduced rainfall. For reviews of aerosol effect on dynamics and microphysics of clouds, see Khain (2009) and Levin and Cotton (2009).

Several studies such as Khain et al. (2008, 2010) and Zhang et al. (2007, 2009) specifically focused on aerosol effects on hurricanes. The latter two examined the impacts of dust acting as CCN. Zhang et al. (2009) revealed a nonmonotonic response such that increases in $\mathrm{CCN}$ concentrations weakened the storm, while further increases in $\mathrm{CCN}$ concentrations either strengthened or had no impact, and further increases led to a decrease in storm intensity. That study did not reveal why such peculiar behavior should occur. We hypothesize that much of that variability was due to the variable intensity of outer rainband convection when the enhanced $\mathrm{CCN}$ advected into that region. Moreover, the environmental $\mathrm{CCN}$ are not always transported from the storm environment into outer rainband convection as it is at the mercy of the local flow in those regions. Furthermore the hurricane is a huge aerosol scavenging machine such that

Published by Copernicus Publications on behalf of the European Geosciences Union. 
virtually none of the dust made its way into the interior of the storm owing to strong washout.

The cold-pool downdraft emanating from the peripheral rainbands can potentially act to cut off the inflow of warm low-level air, a requisite in maintaining the energetics of the system (Wang, 2002; Frisius and Hasselbeck, 2009). For this reason and motivated by Zhang et al's simulations, Cotton et al. (2007) hypothesized that seeding hurricanes with pollution-sized aerosols could lead to a chain of responses leading to the eventual mitigation of the storm intensity. In the outer rainbands, increasing $\mathrm{CCN}$ concentration results in reduced collision/coalescence, increased supercooled water aloft, enhanced convection (latent heat of freezing) and ultimately enhanced precipitation and low level cooling (evaporation). The increase in low level cold-pool coverage in the outer rainband region blocks the flow of energy into the storm core inhibiting the intensification of the tropical TC. However, the amount of suppression of the strength of the $\mathrm{TC}$ depends on the timing between the transport of $\mathrm{CCN}$ to the outer rainbands and the intensity and lifecycle stage of the outer rainband convection. The outer rainband convection needs to be strong in order for the transport of supercooled liquid water aloft to take place. Note that Rosenfeld et al. (2007) arrived at a similar hypothesis using an entirely different dynamic model with simplified bulk microphysics.

While much of the motivation of this work was to investigate the potential for hurricane mitigation by seeding with small hygroscopic aerosol, the results contribute to our understanding of the importance of outer rainband convection and associated rainfall-induced cold-pools on hurricane intensity. As such, it is a complimentary investigation to the recent study by Riermer et al. (2010) in which they find that shear-induced downdrafts in the outer rainband convection of a hurricane can flush the boundary layer with low $\theta_{\text {eair }}$ which in our language interferes with the flow of enthalpy into the storm interior resulting in a weakening of the storm. While aerosol modulation of outer rainband convection is much more subtle than shear-induced changes, our results show a storm response that is consistent with that driven by wind shear.

In this paper, we use the Regional Atmospheric Modeling System developed at Colorado State University (Cotton et al., 2003) that simulates "virtual flights" during which CCN particles are releases as an aircrafts flies at an altitude slightly lower than cloud base and at several seeding times and using different aerosol release rates. Results clearly support the aforementioned hypothesis, as seeding flights increased the quantities of supercooled liquid water, peak updrafts, and lowered the temperature of the cold-pools. More importantly, the peak surface winds show a significant sensitivity to both the seeding time and the aerosol release rates. Moreover, the results suggest there is an optimum CCN release rate; too much $\mathrm{CCN}$ thrusts more water substance into the storm anvils, lowering storm precipitation efficiency and short-circuiting the reduction in surface winds.
A brief description of the model we used is given in Sect. 2. In Sect. 3, we describe the model configuration and give the design of the numerical sensitivity experiments. Results and conclusions are presented in Sects. 4 and 5, respectively.

\section{Model description}

The dynamical modeling framework used for this study is RAMS (Pielke et al., 1992; Cotton et al. 2003) developed at Colorado State University (RAMS@CSU). This non-hydrostatic model integrates predictive equations for the wind components, the Exner function, the ice-liquid water potential temperature, and the total mixing ratio on a vertically-stretched Arakawa C-grid.

The two-moment "bin-emulating" microphysical model (Saleeby and Cotton, 2004, 2008) predicts the mass mixing ratios and number concentrations of various hydrometeor species and cloud-nucleating aerosols. A large-cloud-droplet mode (small drizzle drops) is considered in combination with the traditional single mode of cloud droplets. This permits the representation of the bimodal distribution of cloud droplets that is often seen in clouds (Hobbs et al., 1980). This mode plays a significant role in the collision-coalescence process by resulting in droplets to grow at a slower rate rather than being transferred directly from the first cloud droplet mode to rain. There is also a significant impact of drizzle drops mode upon ice formation, because two modes now exist and are allowed to participate in homogeneous freezing nucleation, freezing by collisions with ice particles, and secondary ice production through the Hallett-Mossop processes. Therefore, this detailed microphysical framework is of great importance for this study as it allows a better representation of numerous microphysical mechanisms affecting the microphysical structure of the storms.

The predicted microphysical variables include the number concentrations and mixing ratios of cloud droplets, drizzle drops, rain, pristine ice, snow, aggregates, graupel and hail(frozen raindrops), as well as the concentrations of ice nuclei (IN), CCN and giant CCN (GCCN). These aerosol concentrations can be defined as vertically and/or horizontally heterogeneous variables that can be advected and diffused, and have sinks due to their activation. The concentration of $\mathrm{CCN}$ nucleated to become cloud droplets is obtained from a lookup table as a function of CCN concentration, vertical velocity, and temperature, using a Lagrangian parcel-bin model (Saleeby and Cotton, 2004) assuming the aerosol are ammonium sulfate. The lookup table is generated previously (offline) from detailed parcelbin model calculations (Feingold and Heymsfield, 1992). The total number of haze particles is a model forecast variable which can be advected and diffused. It also has sinks due to nucleation to form cloud droplets and sources as cloud 
droplets are evaporated. Drizzle drops mainly form by selfcollection among cloud droplets although they can also be independently nucleated via activation of giant CCN (GCCN). GCCN are considered to be composed of $\mathrm{NaCl}$ and their activation is also taken into account using nucleation lookup tables created by a Lagrangian bin-parcel model (for more details see Saleeby and Cotton, 2004).

Vapor deposition, droplet and ice particle collection, and hydrometeor sedimentation are all performed in the scheme. Snow is defined as larger pristine ice crystals $(>100 \mu \mathrm{m})$, which have grown by vapor deposition and riming, while aggregates are defined as ice particles formed by collision and coalescence of pristine ice, snow or other aggregates. The number of pristine ice crystals $\left(N_{\text {pris }}\right)$ predicted due to deposition-condensation freezing is:

$$
N_{\text {pris }}=N_{\mathrm{IN}} \exp \left\{-0.639+01296\left[100\left(\mathrm{~S}_{i}-1\right)\right]\right\}=N_{\mathrm{IN}} F_{\mathrm{M}}
$$

where the exponential expression is the Meyers et al. (1997) formula derived from flow diffusion chamber data sets, $F_{\mathrm{M}}$ represents the fraction of available IN that are activated as a function of ice supersaturation $\left(\mathrm{S}_{i}\right)$, and $N_{\mathrm{IN}}$ is the maximum concentration of IN available for activation. $F_{\mathrm{M}}$ is maximized (equal to 1 ) for these simulations at an ice supersaturation of $40 \%$. The variable $N_{\mathrm{IN}}$ is a forecast variable, and is advected, diffused, and has sinks due to ice activation.

In addition, homogeneous freezing of cloud droplets and haze particles is done following DeMott et al. (1994). Supercooled raindrops freeze by collecting ice crystals. Ice multiplication by the rime-splinter process is parameterized following Mossop (1978) as described in Cotton et al. (2003). The two-stream radiative transfer model used for this study solves the radiative transfer equations for three gaseous constituents, $\mathrm{H}_{2} \mathrm{O}, \mathrm{O}_{3}$, and $\mathrm{CO}_{2}$, and the optical effects of the hydrometeor size spectra (including drizzle drops). Gaseous absorption is calculated by following the fast exponential sum fitting of transmissions method proposed by Ritter and Geleyn (1992). Lorenz-Mie theory is used to compute the optical properties for water drops, while the theory of Mitchell et al. (1996) is used for non-spherical ice crystals. For each hydrometeor species, the band-averaged values of optical properties are computed for the assumed gamma distribution basis function following the method of Slingo and Schrecker (1982).

\section{Model configuration and experimental design}

RAMS@CSU was configured to have three two-way interactive nested grids with 40 vertical levels. The horizontal grid spacing were 24,6 and $1.5 \mathrm{~km}$ for grids 1 to 3 , respectively. The corresponding domain sizes were $1536 \times 1526 \mathrm{~km}, 612.5 \times 612.5 \mathrm{~km}$, and $304 \times 304 \mathrm{~km}$. The centers of all grids and that of the storm were approximately coincident $\left(\sim 15^{\circ} \mathrm{N}, 40^{\circ} \mathrm{W}\right)$. The corresponding time steps were 60,20 , and $2.5 \mathrm{~s}$. The idealized TC simulations were similar to those of Zhang et al. $(2007,2009)$ except for recent updates in the model. For this study we implemented a prognostic scheme (based on the O' Dowd diagnostic formulae (1997) to take into account sea-spray sources for the film, jet, and spume modes which act as CCN and GCCN, respectively. The values predicted by the O' Dowd formulae for the current surface winds were nudged at first model level. In addition, we added modules to take into account the scavenging of various types of aerosols by drizzle and raindrops. These routines (separately) compute scavenging of $\mathrm{CCN}, \mathrm{GCCN}$ as well as the film, jet, and spume sea-spray modes by drizzle and raindrops spectra. Scavenging coefficients are calculated as functions of aerosol size and precipitation rates at each model grid cell; they use curves derived from empirical data (Chate, D., personal communication, 2009).

In order to examine the chain of responses to the introduction of enhanced CCN concentrations in TCs, we performed a rather large number of multi-grid numerical experiments. Those simulations were homogeneously initialized with clean (maritime) concentrations and used a code that simulates the flight of a plane and increases the CCN concentrations as an aircraft flies following different trajectories. Flight times varied between simulation times 36 and $42 \mathrm{~h}$ for the runs corresponding to results presented in this paper. This 6-h interval corresponds to a period of intensification of the simulated storm. Virtual flights performed more $6 \mathrm{~h}$ after the end of the spin-up time (simulation time $36 \mathrm{~h}$ ) produced significantly less important effects. The aerosol release rates during these virtual flights were also varied. However the numerical experiments will be identified by the $\mathrm{CCN}$ concentration in the grid cells along the trajectory. All virtual flights were performed at an altitude slightly lower than cloud base height $(\sim 2000 \mathrm{~m})$ and the aircraft speed was $150 \mathrm{~m} \mathrm{~s}^{-1}$. Figure 1 schematically represents two internal radius and external virtual flights some runs combined internal and external flights.

\section{Results}

\subsection{Vertical motions, supercooled liquid water and precipitation}

The time evolution of the simulated TCs soon after the corresponding seeding flights exhibited a common pattern with regard to vertical motion, supercooled liquid water mass, and precipitation. In general, updraft maxima simulated within the outer rainbands and the altitude at which they occur increased approximately $3 \mathrm{~h}$ after the corresponding seeding flight. This invigoration of the convection along the aerosol plume was associated with an important increase in the supercooled liquid water contents that enhances the production of aggregates and eventually precipitation. 
Table 1. Old-pool analyses for different seeding times, flight types, and aerosol release rates. $\Delta T$ and $\Delta \theta_{e}$ are cold-pool temperatures and $\theta_{e}$ differences with respect to the average horizontal. $\Delta T_{\mathrm{G} 3}$ and $\Delta \theta_{e G 3}$ correspond to first model level values differences with respect the control run.

\begin{tabular}{llrrrrrrr}
\hline Time & Type & $\begin{array}{r}\mathrm{CCN} \\
\left(\mathrm{cm}^{-3}\right)\end{array}$ & $\begin{array}{r}\text { Mean area } \\
\left(\mathrm{km}^{2}\right)\end{array}$ & $\begin{array}{r}\text { Max area } \\
\left(\mathrm{km}^{2}\right)\end{array}$ & $\begin{array}{r}\Delta T \\
(\mathrm{~K})\end{array}$ & $\begin{array}{r}\Delta \theta_{e} \\
(\mathrm{~K})\end{array}$ & $\begin{array}{r}\Delta \mathrm{T}_{\mathrm{G} 3} \\
(\mathrm{~K})\end{array}$ & $\begin{array}{r}\Delta \theta_{e G 3}^{\prime} \\
(\mathrm{K})\end{array}$ \\
\hline- & - & 0 & 26.3 & 49.5 & -5.29 & -23.65 & 0.00 & 0.00 \\
36 & int & 8000 & 50.6 & 288.0 & -5.68 & -25.88 & -0.06 & -0.31 \\
36 & ext & 8000 & 67.1 & 180.0 & -5.45 & -24.86 & -0.05 & -0.31 \\
42 & ext & 8000 & 76.1 & 292.5 & -6.77 & -28.32 & -0.03 & -0.16 \\
39 & both & 8000 & 49.8 & 141.8 & -5.38 & -24.32 & -0.06 & -0.32 \\
36 & both & 8000 & 26.8 & 67.5 & -5.29 & -23.88 & -0.03 & -0.15 \\
42 & both & 8000 & 100.4 & 357.7 & -5.57 & -25.61 & -0.14 & -0.83 \\
$\mathbf{3 9}$ & ext & $\mathbf{8 0 0 0}$ & $\mathbf{6 9 . 5}$ & $\mathbf{3 5 7 . 8}$ & $-\mathbf{5 . 6 8}$ & $-\mathbf{2 5 . 8 9}$ & $-\mathbf{0 . 1 4}$ & $-\mathbf{0 . 8 3}$ \\
39 & ext & 6000 & 88.9 & 299.3 & -5.66 & -25.29 & -0.13 & -0.77 \\
39 & ext & 4000 & 25.9 & 49.5 & -5.32 & -24.24 & -0.05 & -0.36 \\
\hline
\end{tabular}

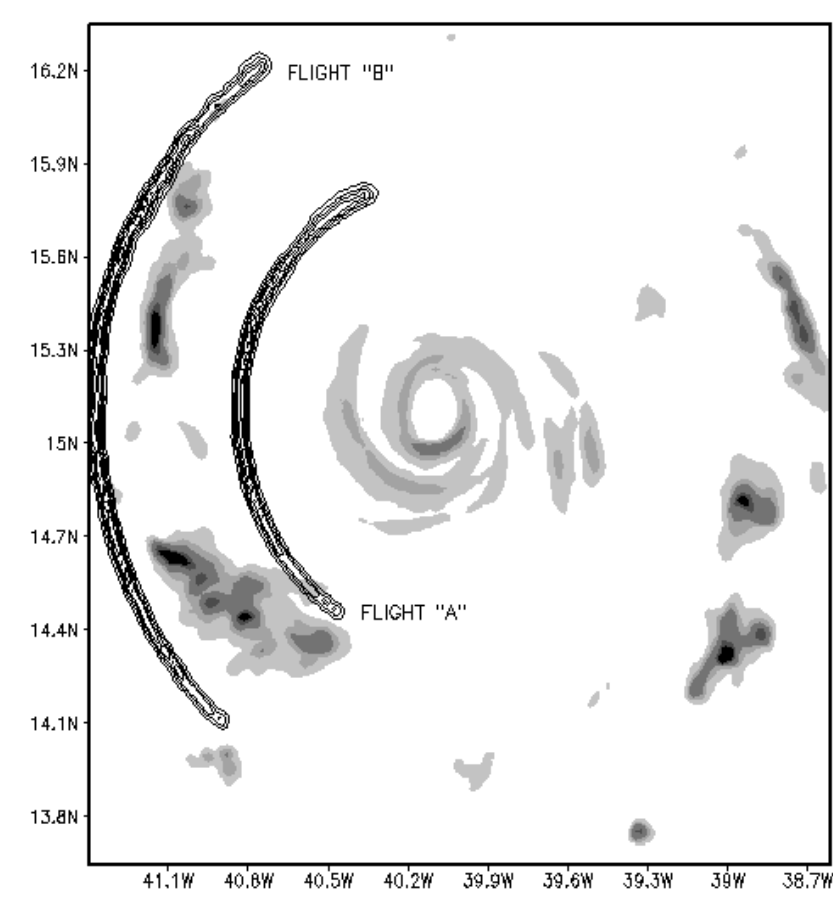

Fig. 1. Virtual flights over internal and external radii. For the combined trajectory, the aircraft would fly north following flight "A" and then south along flight "B". Black contours denote aircraft flight paths and shaded areas locate convective activity (liquid water path).

Figures 2-5 illustrate this chain of early effects on the TC evolution for an external radius flight at time $39 \mathrm{~h}$ and $8000 \mathrm{~cm}^{-3}$ along the trajectory. This numerical experiment, as discussed in the following subsections produced the most dramatic impact on storm evolution. Figures 2 and 3 compare the supercooled (SC) liquid water mixing ratios simulated for this virtual flight (panel b) to that of the control run (panel a) for time of the flight (simulation time $39 \mathrm{~h}$ ) and $3 \mathrm{~h}$ later ( $42 \mathrm{~h}$ ), respectively. Naturally, no differences can be seen at SC levels at the time the aerosols are released right below cloud (Fig. 2). The expected aerosol plume location is approximately indicated by an arrow in Fig. 2b. Along this aerosol plume, important differences in the simulated SC liquid water isosurfaces are evident when comparing these two runs three hours later (Fig. 3a and b). For instance, the integral mass of SC liquid water at simulation time $42 \mathrm{~h}$ (computed as the spatial integration of the SC liquid water contents) was almost 30\% higher than that of the control run. Vertical motion was significantly affected along the aerosol plume as can be seen in Fig. 4 that shows updraft isosurfaces. The altitudes at which updraft maxima occurred were between 800 and $1900 \mathrm{~m}$ above those of the control run between simulation times 42 and $45 \mathrm{~h}$, (not shown). The rapid freezing of these larger amounts of SC droplets via riming produces a significant increase in the production aggregates as can be seen in Fig. 5 that gives the mixing ratios of this species for simulation time $42 \mathrm{~h}$. The precipitation accumulated between time 39 and $43 \mathrm{~h}$ (the four hours following the virtual flight) is compared in Fig. 6. A significant impact is evident over the aerosol plume. The integral volume of precipitation during these four hours after the virtual flight simulation was approximately $15 \%$ higher than that corresponding to the control run. However, the integral volume of the seeded run between 39 and $72 \mathrm{~h}$ was approximately $10 \%$ lower than that of the control run

\subsection{Cold-pools}

We computed probability density functions (PDFs) of coldpool size for numerical experiments using grid 3 model outputs every $30 \mathrm{~min}$. Cold-pools were defined as groups of contiguous grid cells that had temperatures at least $4{ }^{\circ} \mathrm{C}$ lower that the horizontal domain-average at the corresponding time. The main results are summarized in Table 1. 

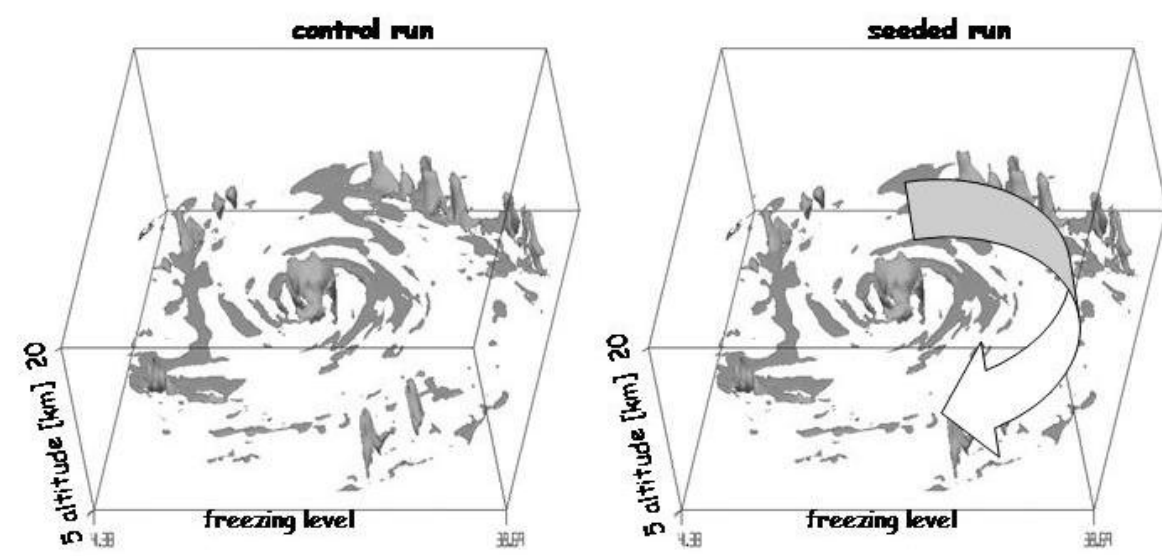

Fig. 2. Supercooled liquid water at simulation time $39 \mathrm{~h}$ for the control run and seeded run. Isosurfaces correspond to the $1 \mathrm{~g} \mathrm{~kg}^{-1} \mathrm{level}$. The arrow denotes the approximate location of the aerosol plume. The base of the shown subdomain is the freezing level.
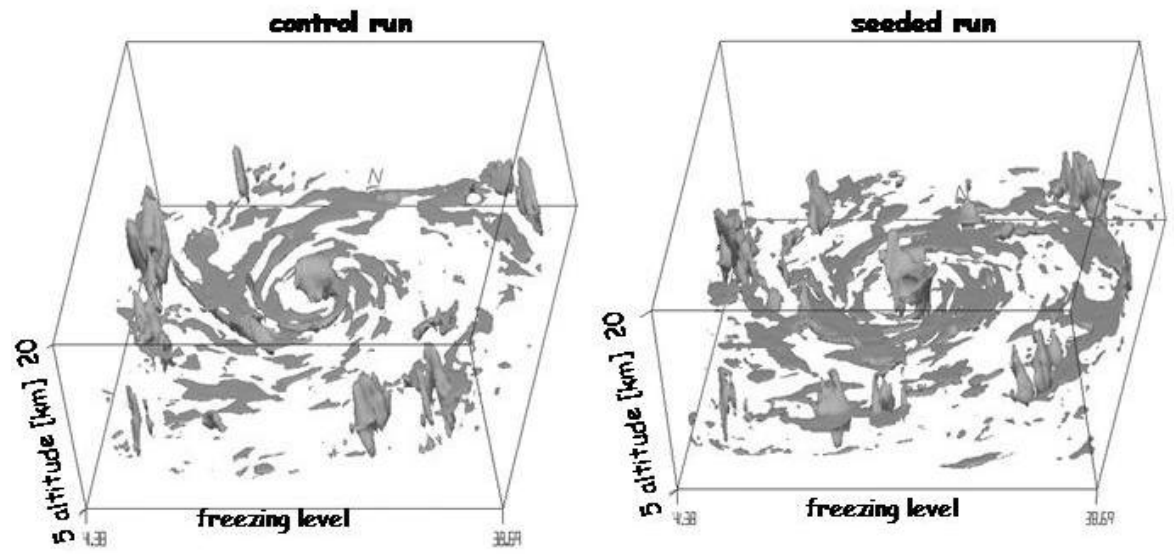

Fig. 3. Comparison of supercooled liquid water at simulation time $42 \mathrm{~h}$, three hours after the seeding flight. Mixing ratio Isosurfaces correspond to the $1 \mathrm{~g} \mathrm{~kg}^{-1}$ level.

Numerical experiments considered, different seeding times and aerosol release rates, and internal and external trajectories (with respect to the outer rainbands) as well as their combination. In general, simulated seeding flights produced cold-pool distributions with expected (mean) areas considerably higher than that of the control run. It must be noted that, the expected cold-pool area is four times larger than that of the control run for the virtual flight used for comparisons in the previous subsection (shaded row in Table 1). The PDFs of cold-pool area also showed differences in their tails, indicating higher frequencies of large cold-pools sizes. For instance, the maximum simulated area shows a considerable increase for all sensitivity runs except for the flight at $39 \mathrm{~h}$ and $4000 \mathrm{~cm}^{-3}$. The minimum values of cold pool temperature and the equivalent potential temperature $\left(\theta_{e}\right)$ are given as differences with respect to the horizontally-averaged value for the first model level corresponding to each time. In most cases the temperature and $\theta_{e}$ differences $\left(\Delta T\right.$ and $\Delta \theta_{e}$, respectively) were higher (in absolute value) than those corresponding to the control run (again, the virtual flight at $39 \mathrm{~h}$ and $4000 \mathrm{~cm}^{-3}$ is an exception). Moreover, seeding flights reduced the temperature and $\theta_{e}$ of first model level above ground for the entire grid 3. Temperature and $\theta_{e}$ differences with respect to the control run $\left(\Delta T_{\mathrm{G} 3}\right.$ and $\Delta \theta_{e \mathrm{G} 3}$, respectively) were computed for the first model level and they were spatially averaged over the entire grid 3 and temporally averaged from the seeding time to the end of the simulations. Both $\Delta T_{\mathrm{G} 3}$ and $\Delta \theta_{e \mathrm{G} 3}$ gave negative differences for all runs. These differences may seem small, however, it must be noted that they are temporal averages over the entire finest grid. These differences are the cause of the storm intensity weakening. Moreover, the seeding effects on expected and maximum cold-pool areas are actually underestimates because they have been computed relative to each run's horizontalaveraged values. 

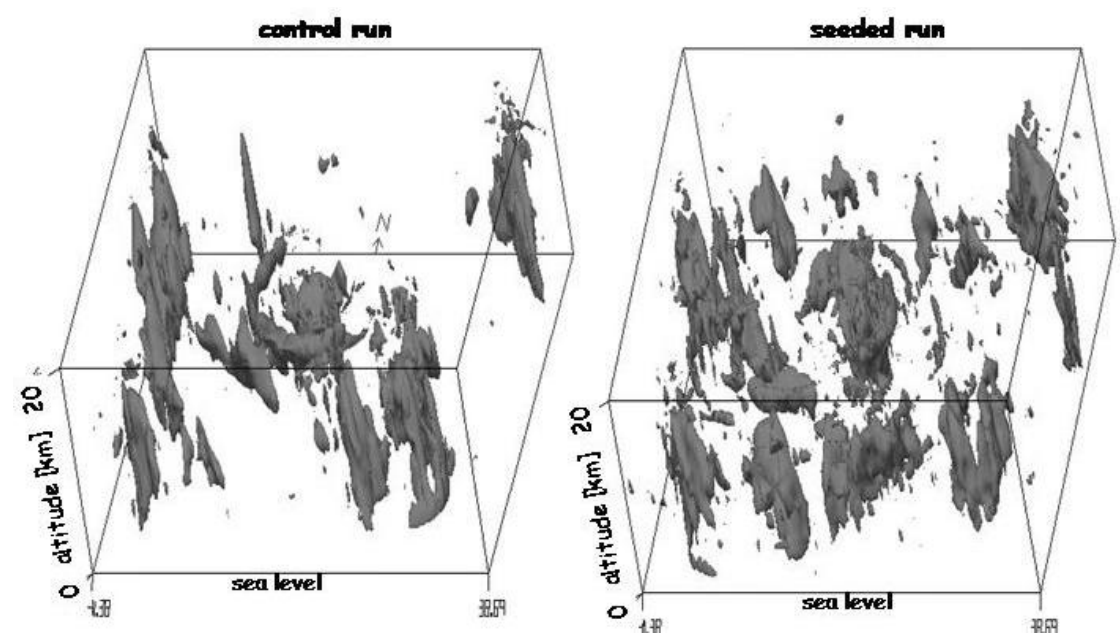

Fig. 4. Idem Fig. 3 but for updrafts; isosurfaces correspond to the $5 \mathrm{~m}^{-1}$ level.
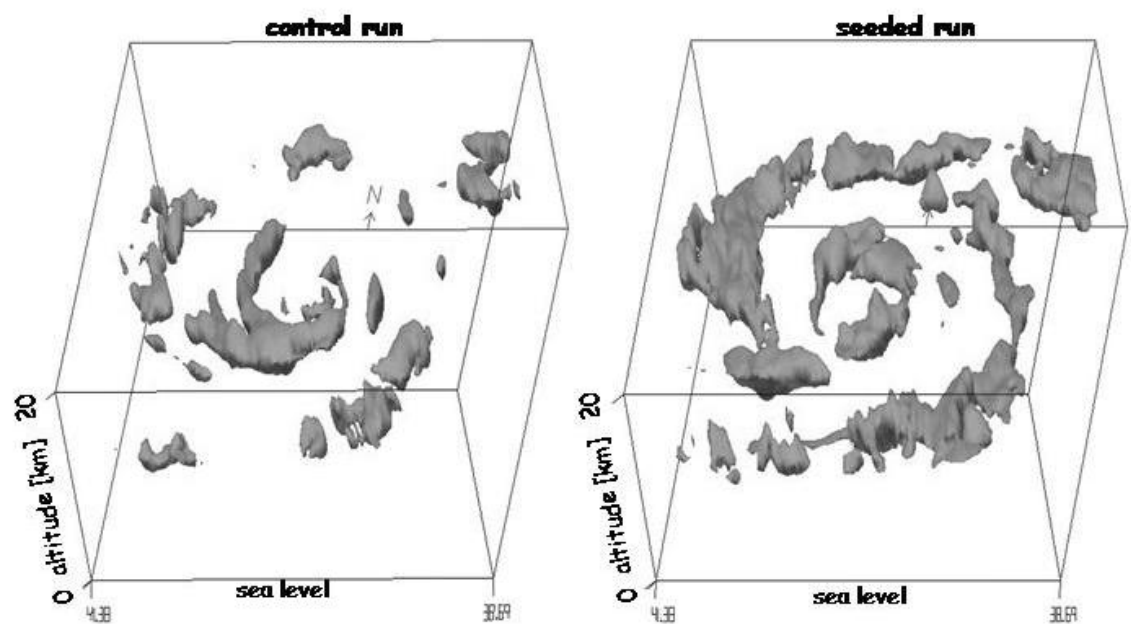

Fig. 5. Idem Fig. 4 but for the mixing ratio of aggregates; isosurfaces correspond to the $1.2 \mathrm{~g} \mathrm{~kg}^{-1}$ level.

We performed several other experiments using the virtual flight trajectory of the experiment highlighted in Table 1 to cover a CCN concentration range from 2000 to $16000 \mathrm{~cm}^{-3}$. The corresponding results are given in Table 2. It is interesting to note the clearly monotonic behavior of various quantities when $\mathrm{CCN}$ concentrations vary between 2000 and $8000 \mathrm{~cm}^{-3}$. However, it can be seen that there is a change of response above $8000 \mathrm{~cm}^{-3}$. In particular, the area of the largest cold-pool simulated for the $8000 \mathrm{~cm}^{-3}$ run is six times higher than that of the control run. However, from that peak value, it decreases approximately 3,7 and $10 \%$ for the 10000,12000 , and $16000 \mathrm{~cm}^{-3}$, respectively. The lower level overall cooling $\left(\Delta T_{\mathrm{G} 3}\right)$ is also less important for the latter runs. In order to further analyze the peculiar response of cold pools, we examined the changes in the structures downdrafts in the following subsection.

\subsection{Downdrafts}

We computed the overall downward mass flux and compared the corresponding time-averaged vertical profiles for various numerical experiments considering seeding flights at simulation time $39 \mathrm{~h}$. These overall downward mass were evaluated at $2000 \mathrm{~m}$ and for the period 39-72 h. Downward mass fluxes exhibit a clearly monotonic behavior when the $\mathrm{CCN}$ concentrations (along the trajectory) are increased up to $8000 \mathrm{~cm}^{-3}$ with differences up 15\% compared the control run (Fig. 7a). Conversely, an opposite response is observed in Fig. $7 \mathrm{~b}$ when $\mathrm{CCN}$ concentrations are above this threshold. Nonetheless, downward mass fluxes for both 12000 and $16000 \mathrm{~cm}^{-3}$ runs exceed that of the control run.

Figure $8 \mathrm{a}$ and $\mathrm{b}$ show that the enhanced downward fluxes are not linked (only) to more intense downdrafts but also to 

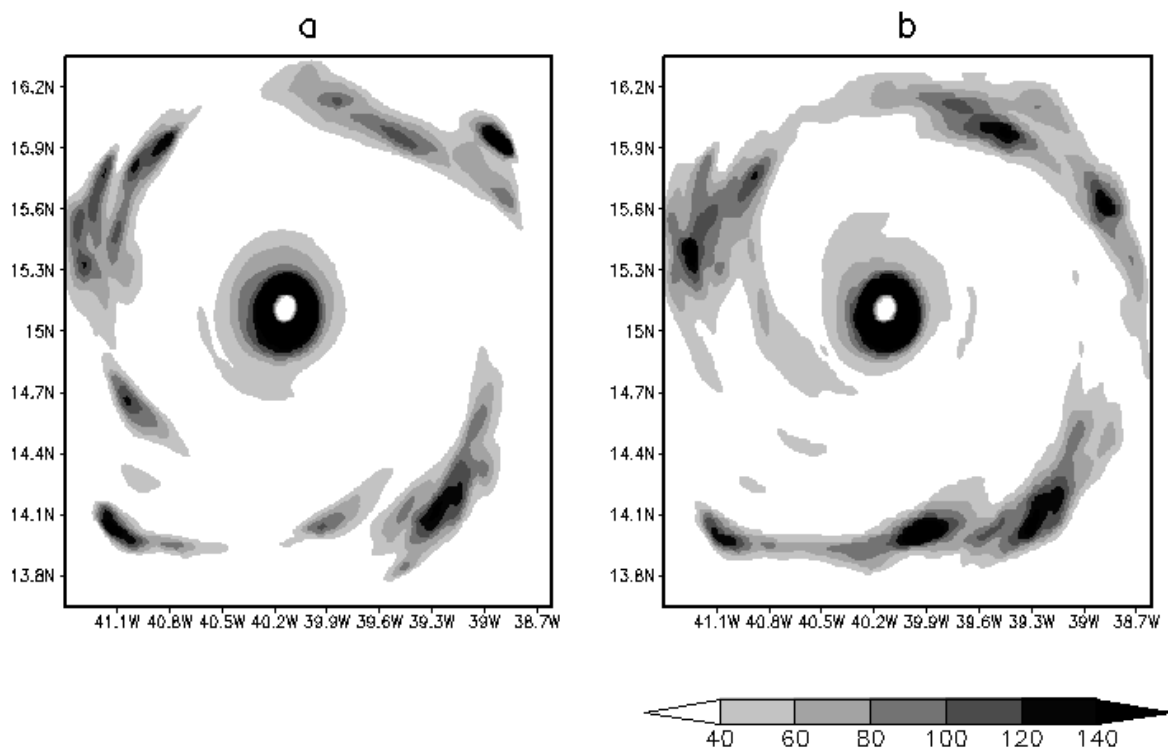

Fig. 6. Precipitation accumulated between hours 39 and 43 for the control run and the seeded run in panels (a) and (b), respectively. Shaded areas represent precipitation in $\mathrm{mm}$.

Table 2. Idem Table 1, but seeding external flights at $39 \mathrm{~h}$ varying aerosol release rates.

\begin{tabular}{lrrrrrr}
\hline $\begin{array}{r}\mathrm{CCN} \\
\left(\mathrm{cm}^{-3}\right)\end{array}$ & $\begin{array}{r}\text { Mean area } \\
\left(\mathrm{km}^{2}\right)\end{array}$ & $\begin{array}{r}\text { Max area } \\
\left(\mathrm{km}^{2}\right)\end{array}$ & $\begin{array}{r}\Delta T \\
(\mathrm{~K})\end{array}$ & $\begin{array}{r}\Delta \theta_{e} \\
(\mathrm{~K})\end{array}$ & $\begin{array}{r}\Delta T_{\mathrm{G} 3} \\
(\mathrm{~K})\end{array}$ & $\begin{array}{r}\Delta \theta_{e G 3} \\
(\mathrm{~K})\end{array}$ \\
\hline 0 & 26.3 & 49.5 & -5.29 & -23.65 & 0.00 & 0.00 \\
2000 & 26.2 & 49.5 & -5.19 & -23.61 & -0.05 & -0.36 \\
4000 & 25.9 & 69.5 & -5.32 & -24.24 & -0.05 & -0.36 \\
6000 & 88.9 & 299.3 & -5.66 & -25.29 & -0.13 & -0.77 \\
8000 & 69.5 & 357.8 & -5.68 & -25.89 & -0.14 & -0.83 \\
10000 & 72.3 & 352.4 & -5.72 & -25.10 & -0.12 & -0.82 \\
12000 & 68.0 & 333.2 & -5.68 & -24.95 & -0.12 & -0.81 \\
16000 & 65.7 & 327.7 & -5.67 & -23.98 & -0.11 & -0.80 \\
\hline
\end{tabular}

larger areas covered by them. The response is again clearly monotonic up to $8000 \mathrm{~cm}^{-3}$. Even though all virtual flights produced a downdraft areal coverage higher than the control run, the values for numerical experiments using 12000 and $16000 \mathrm{~cm}^{-3}$ were between those simulated for $8000 \mathrm{~cm}^{-3}$ and the control run.

We generated statistics selecting the downdrafts linked to the cold-pools of larger area for each model output time (every $30 \mathrm{~min}$ ). As an example, Figure 9 illustrates a detail of the lowest $4000 \mathrm{~m}$ of the downdraft (dark gray) associated to the largest cold-pool (light gray) simulated for these numerical experiments (virtual flight at $39 \mathrm{~h}$, $8000 \mathrm{~cm}^{-3}$ ). Figures $10-12$ compare average vertical profiles of the aforementioned downdraft composites for various runs. All runs considering virtual flights sensitivity produced buoyancy values higher (more negative) than those of the control run. Buoyancy within the lowest $1000 \mathrm{~m}$ exhibits a monotonic response to $\mathrm{CCN}$ concentrations lower or equal to $8000 \mathrm{~cm}^{-3}$ (Fig. 10a). However, upon further enhancing aerosol concentrations produces the opposite effect (Fig. 10b). Figure 11a and b are analogous to Fig. 10a and $b$ but they give rain mixing ratio vertical profiles. It can be seen that rain mixing ratios exhibit an identical pattern of response. However, this change of behavior is not observed when comparing the mean mass diameters of raindrops within the most intense downdrafts (Fig. 12). In this case, raindrop diameters monotonically decrease when increasing CCN concentrations from 2000 to $16000 \mathrm{~cm}^{-3}$.

\subsection{Surface winds}

Surface winds exhibited the same pattern of response that was observed for the area and intensity of cold-pools and downdrafts, as well as the buoyancy and the rain mixing ratio within the latter. Figure 13 compares surface wind frequencies corresponding to seeding flights numerical experiments 

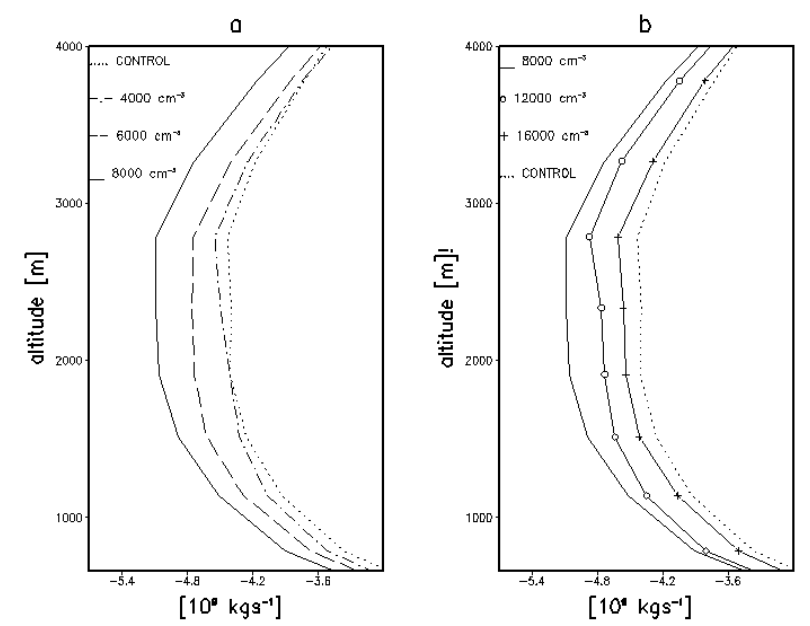

Fig. 7. Integral downward mass transport computed for the control run and the seeded run in panels (a) and (b), respectively. Vertical profiles correspond to temporal averages over the 24-h period after the flight.
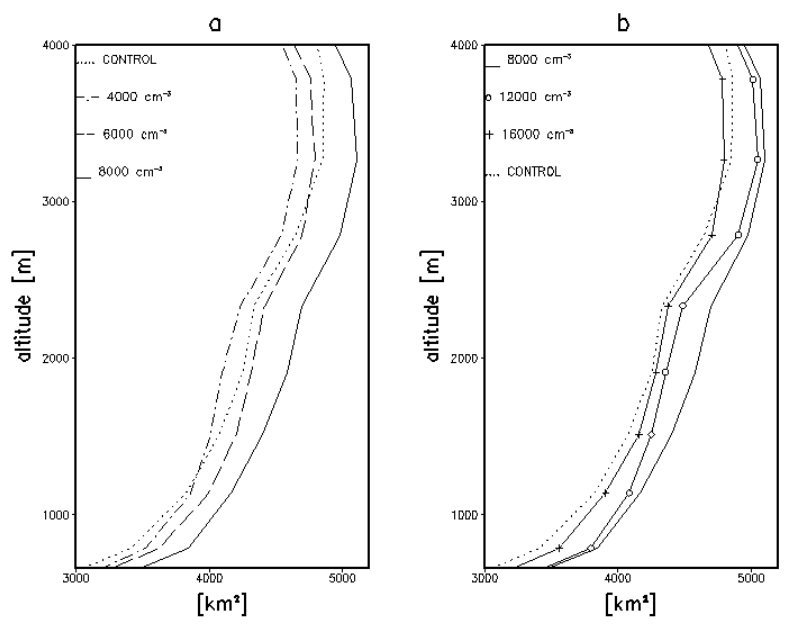

Fig. 8. Idem Fig. 7 but for the area covered by downdrafts.

to those of the control run. This plot used model output data for a time period from seeding time $(39 \mathrm{~h})$ to the end of the simulations. The frequencies of the highest surface winds for the control run are approximately 6 times larger than those corresponding to the $8000 \mathrm{~cm}^{-3}$ run. For category 5 wind speed range, reductions of 30,50 , and $60 \%$ were simulated for runs using 4000, 6000, and $8000 \mathrm{~cm}^{-3}$, respectively. These experiments also produced an approximate reduction of $30 \%$ for surface winds within category 4 and a minimum reduction $20 \%$ was simulated for all other hurricane categories. Figure 14 is analogous to Fig. 13 but for the higher $(\mathrm{CCN})$ range along the virtual flight trajectory. This figure shows that the reduction in the frequency of category 5 winds falls from $60 \%$ to 35 and $7 \%$ when comparing the 8000,12000 and $16000 \mathrm{~cm}^{-3}$ runs, respectively.

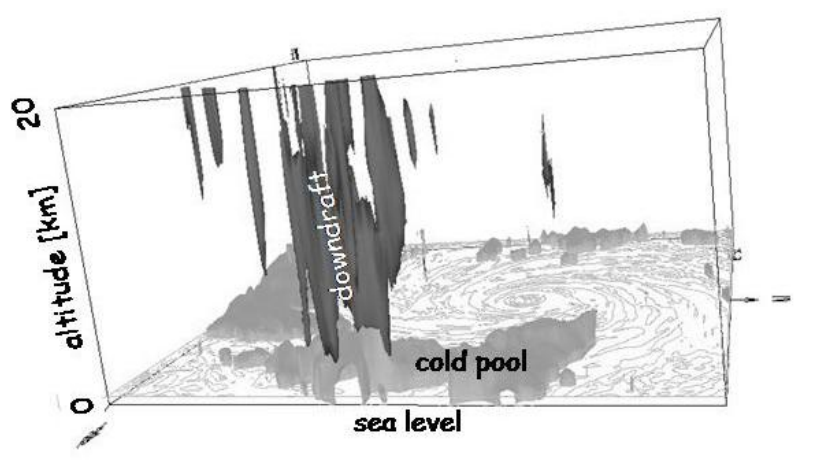

Fig. 9. The largest simulated cold pool and its associated downdraft. The isosurface representing the cold pool (light gray) corresponds to a temperature difference of $-4 \mathrm{~K}$ with respect to the horizontal average (for each level). Downdraft isosurface (dark gray) correspond to $-2 \mathrm{~ms}^{-1}$.
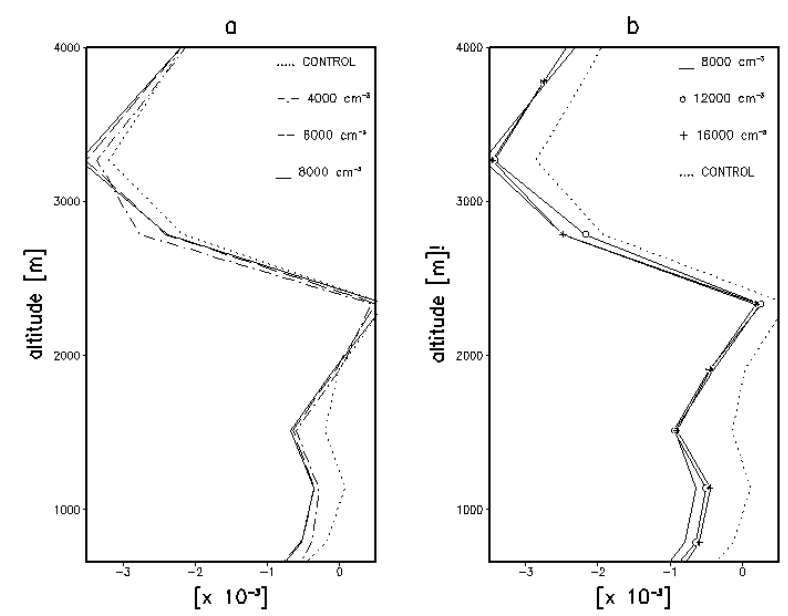

Fig. 10. Comparison of buoyancy within the most intense downdrafts for the control run and the seeded run in panels (a) and (b), respectively.

Simulated surface winds with hurricane intensities were compared range in Figs. 13 and 14 for the entire finest grid. Figure 15 compare surface winds frequency density functions simulated for the control run (dotted lines) and the run using $8000 \mathrm{~cm}^{-3}$ (solid lines) for two subdomains. One area corresponds to gridcells with a radial distance to the storm center $(R)$ lower $90 \mathrm{~km}$ containing the core of the storm but excluding the outer rainbands. Conversely, the second area corresponds to gridcells with $R>90 \mathrm{~km}$ containing the outer rainbands but excluding the core of the storm. For the storm core, seeding reduces the occurrence of frequencies within the hurricane range of winds (surface winds higher than $33 \mathrm{~m} \mathrm{~ms}^{-1}$ ). For $R>90 \mathrm{~km}$, seeding increases frequencies due to the intensification of convection in the outer bands, however, it must be noted that maximum winds simulated for $R>90 \mathrm{~km}$ were significantly lower than those of the core. 

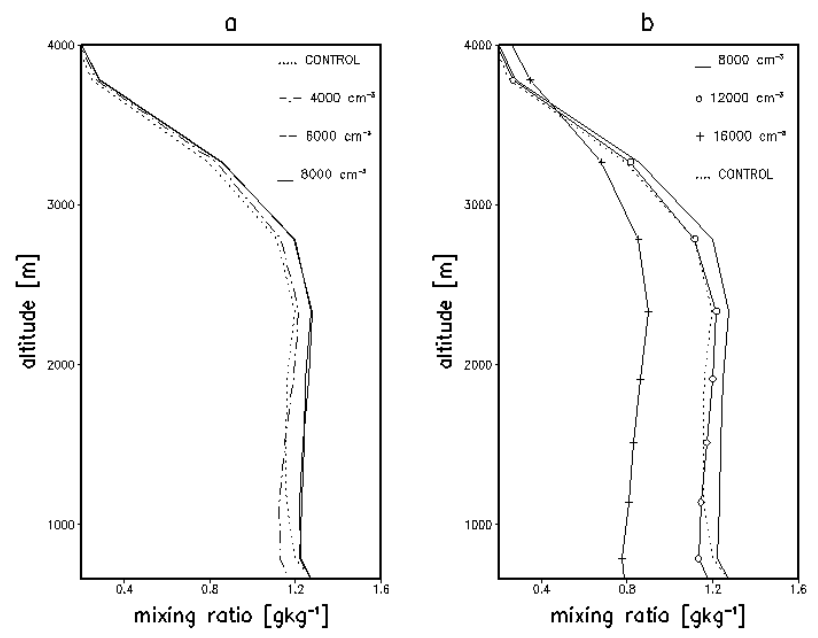

Fig. 11. Idem Fig. 10 but for rain mixing ratio.
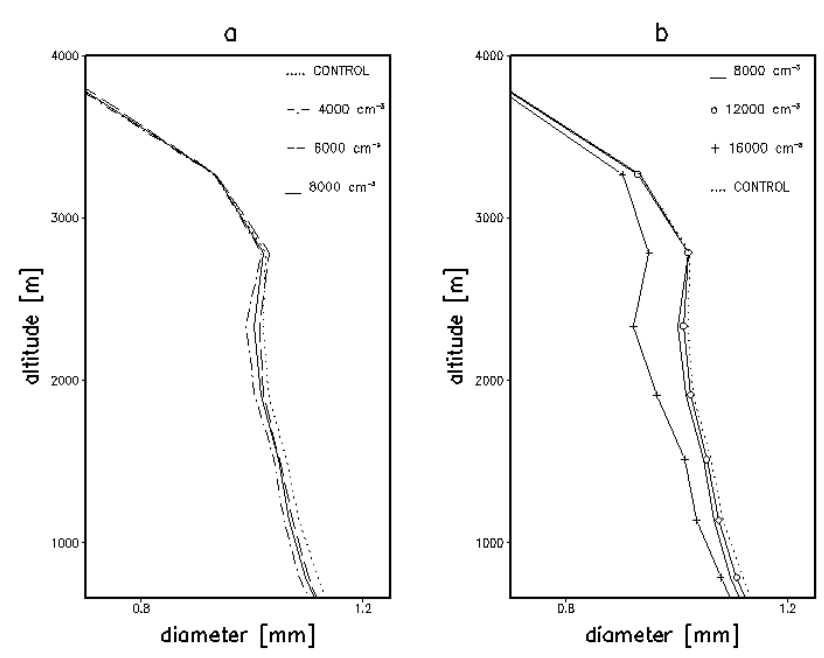

Fig. 12. Idem Fig. 10 but for raindrop mean mass diameters.

\section{Conclusions}

We performed a series of multi-grid cloud-resolving simulations to examine the response of a simulated hurricane to the targeted insertion of CCN. The modeling framework included improved microphysical modules that include a binemulating treatment of riming processes, sea-salt surface sources in three modes, sinks for cloud nucleating particles due to scavenging by precipitation, and a code that simulates the targeted insertion of CCN by aircraft.

Virtual seeding flights cause a reduction of collision and coalescence, resulting in more supercooled liquid water to be transported aloft. This supercooled liquid water enhances latent heat of freezing which produces higher updraft maxima at higher altitudes. Results also suggest that the higher evaporative cooling from enhanced rainfall rates in the outer rainbands produces stronger and more widespread cold-pools.

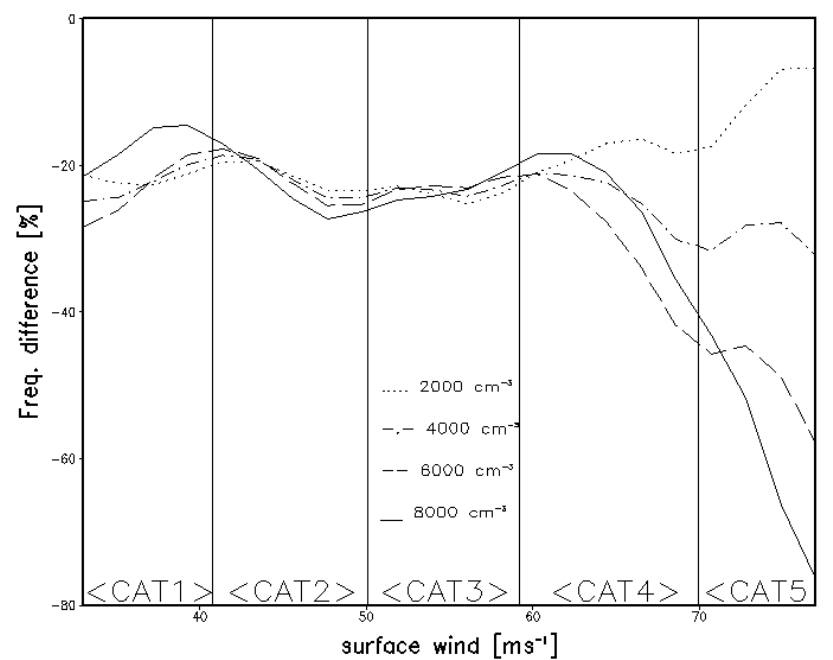

Fig. 13. Comparison of hurricane intensity surface wind frequencies for flights with $\mathrm{CCN}$ concentrations below $8000 \mathrm{~cm}^{-3}$. Curves represent percent differences with respect to the control run.

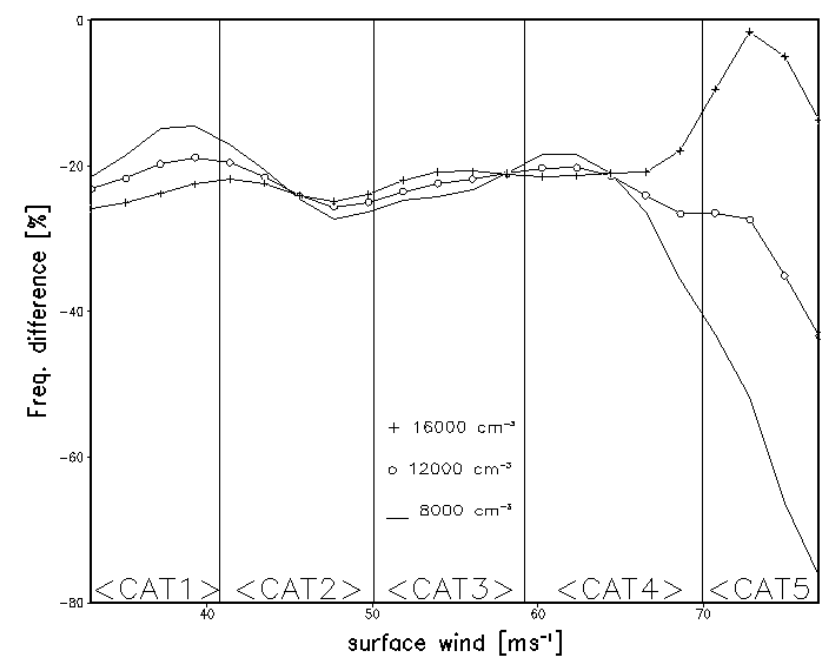

Fig. 14. Idem Fig. 13 but for flights with $\mathrm{CCN}$ concentrations above $8000 \mathrm{~cm}^{-3}$.

Results indicate a clear and significant response of cold-pools that cover larger areas and interfere with the flow of enthalpy into the storm core and therefore weaken the storm. However, this mechanism cannot be univocally linked to the mitigation of the intensity of the simulated. For instance, other mechanisms could be preventing a rapid intensification of the storm provided the simulated invigoration of convective activity in the outer rainbands (see Bister, 1997, 2001). Sublimation of ice crystals could also be playing a non negligible role; however, Zhang et al. $(2007,2009)$ performed a heating analysis that led to the conclusion that the main response was at low-levels. Riemer et al. (2010) also finds evidence that the invigoration of convective activity in the outer rainbands 

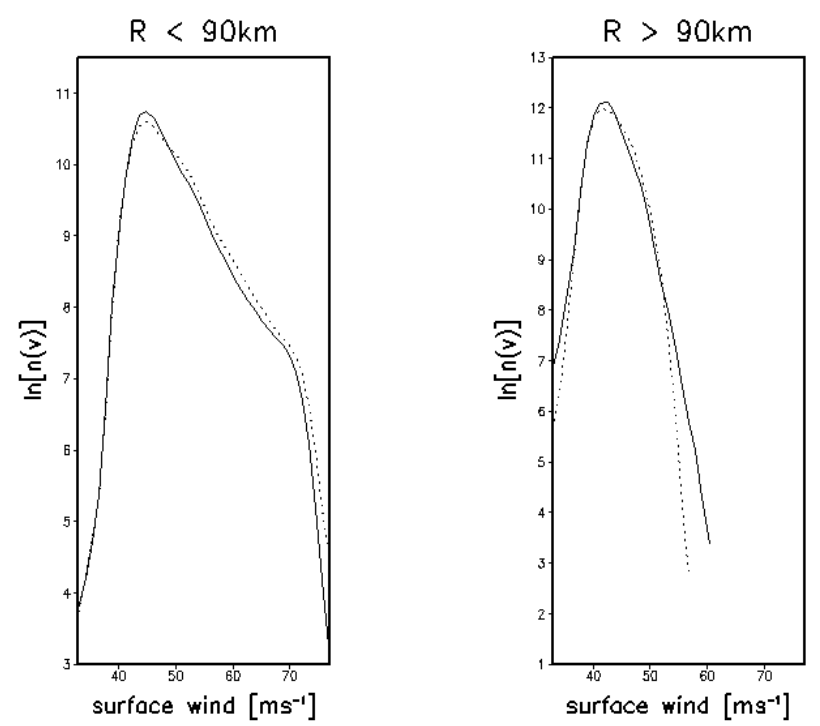

Fig. 15. Tangential wind density functions for two subdomains. One targeting the storm core $(R<90 \mathrm{~km})$ and the other the outer rainbands $(R>90 \mathrm{~km})$. Dotted and solid lines denote the control and the seeded runs, respectively.

leads to a reduction in TC intensity. That study focused on the role of vertical wind shear on the TC inflow layer.

The increase in cold-pool spatial physical dimensions as well as the temperature difference with respect to their surrounding environment was clearly linked to the enhanced aerosol concentrations, mainly due to the monotonic response they exhibited when increasing $\mathrm{CCN}$ concentrations up to $8000 \mathrm{~cm}^{-3}$. A similar monotonic response was observed for the overall downward flux, the area covered with downdrafts as well as the buoyancy, rain mixing ratio, and (decreasing) raindrop size within the downdrafts associated with the larger cold-pools. Moreover, simulated reduction in frequencies of high surface winds behaved in a similar manner. Nonetheless, with the exception of raindrop sizes, all of the aforementioned quantities exhibited a different response when we considered concentrations above $8000 \mathrm{~cm}^{-3}$ along the flight trajectories. This change of behavior was seen in simulated sea-breeze-induced storms over Houston Carrió et al. (2010) and Carrió and Cotton (2011). Briefly, further enhancing $\mathrm{CCN}$ concentrations reduces the size of supercooled droplets, which reduces riming growth of ice particles which results in the transport of a greater fraction of the ice-phase water mass to anvil levels as pristine ice crystals instead of being precipitating to the surface. A similar behavior was examined for single convective cells by Wang (2005) and Khain (2009).
In summary, the primary impact of aerosols on TC genesis and intensity is by altering the strength of cold-pools. The idea that cold-pools are an important modulator of TC intensity is consistent with observations that TC rapid intensification follows the formation of a nearly saturated core (results in weak cold-pools). It is also consistent with strong vertical wind shear as being a detriment to TCs (strong shear enhances entrainment of dry air increasing cold-pool strengths) as shown by Riemer et al. (2010). We speculate that during TC genesis vigorous cold-pools can lead to vertical decoupling between a mid-level MCV and low-level vorticities similar to what we find with tornadoes (Lerach et al., 2009). Vigorous cold-pools in mature TCs can interfere with the flow of enthalpy into the storm core.

An implication from this research is that greater attention has to be taken in cold-pool diagnosis for hurricane strength prediction. A remote sensing method of TC coldpools would be ideal to map cold-pool variability in TCs. Furthermore, in order to simulate and predict aerosol impacts on TCs, models need high enough resolution and microphysics to represent convective-scale dynamical responses to aerosols as well as environmental properties affecting cold-pools.

Acknowledgements. This work was supported by a grant funded by the Department of Homeland Security through NOAA (NOAAESRL) contract \# NA17RJ1228.

Edited by: J. Quaas

\section{References}

Bister, M.: Effect of the Coriolis parameter on tropical cyclogenesis: The dominant role of outer convection, J. Atmos. Sci., 58, 3463-3476, 1997.

Bister, M.: Effect of Peripheral Convection on Tropical Cyclone Formation. Preprints, 22d, Conf. on Hurricanes and Tropical Meteorology, Fort Collins, CO, Amer. Meteor. Soc., 553-554, 2001.

Carrió, G. G., Cotton, W. R., and Cheng W. Y. Y.: Urban growth and aerosol effects on convection over Houston, Part I: the August 2000 case, Atmos. Res., 96, 560-574, 2010

Carrió, G.G. and Cotton, W. R.: Effects of the Urban growth of Houston on convection and precipitation, Part II: Dependence of aerosol effects on instability, Atmos. Res., submitted, 2010.

Carrió, G. G., van den Heever, S. C., and Cotton, W.R.: Impacts of nucleating aerosol on anvil-cirrus clouds: A modeling study, Atmos. Res., 84, 111-131, 2007.

Cotton, W. R. and Pielke, R. A.: Human impacts on weather and climate, Cambridge University Press, New York, USA, 288 pp., 2009.

Cotton, W. R., Pielke Sr., R. A., Walko, R. L., Liston, G. E., Tremback, C. J., Jiang, H., McAnelly, R. L., Harrington, J. Y., Nicholls, M. E., Carrió, G. G., and McFadden, J. P.: RAMS 2001: Current status and future directions, Meteor. Atmos. Phys., 82, 5-29, 2003. 
Cotton, W. R., Zhang, H., McFarquhar, G. M., and Saleeby, S. M.: Should we consider polluting hurricanes to reduce their intensity?, J. Wea. Mod., 39, 70-73, 2007

Feingold, G. and Heymsfield, A. J.: Parameterizations of condensational growth of droplets fior use in general circulation models, J. Atmos. Sci., 49, 2325-2342, 1992.

Frisius, T. and Hasselbeck, T.: The effect of latent cooling processes in tropical cyclone simulations, Q. J. Roy. Meteor. Soc., 135, 1732-1749, 2009.

Hobbs, P. V., Politovich, M. K., and Radke, L. F.: The structures of summer convective clouds in eastern Montana, I, Natural clouds, J. Appl. Meteor., 19, 645-663, 1980.

Khain A. P., Rosenfeld, D., and Pokrovsky, A.: Simulation of deep convective clouds with sustained supercooled liquid water down to $-37.5^{\circ} \mathrm{C}$ using a spectral microphysics model, Geophys. Res. Lett., 28, 3887-3890, 2001.

Khain, A., Pokrovsky, A., and Pinsky, M., Seifert, A., and Phillips, V.: Effects of atmospheric aerosols on deep convective clouds as seen from simulations using a spectral microphysics mixedphase cumulus cloud model Part 1: Model description, J. Atmos. Sci, 61, 2963-2982, 2004.

Khain, A., Rosenfeld, D., and Pokrovsky, A.: Aerosol impact on the dynamics and microphysics of convective clouds, Q. J. Roy. Meteor. Soc., 131, 2639-2663, 2005.

Khain, A., Cohen, N., Lynn, B., and Pokrovsky, A.: Possible aerosol effects on lightning activity and structure of hurricanes, J. Atmos. Sci., 65, 3652-3667, 2008.

Khain, A. P.: Effects of aerosols on precipitation: a review: Environ. Res. Lett., Environ. Res. Lett., 4, 015004, doi:10.1088/17489326/4/1/015004, 2009.

Khain, A., Lynn, B., and Dudhia, J.: Aerosol effects on intensity of landfalling hurricanes as seen from simulations with WRF model with spectral bin microphysics, J. Atmos. Sci. 67, 365384, 2010

Lerach, D., Gaudet, B.J., and Cotton, W. R.: Idealized simulations of aerosol influences on tornadogenesis, Geophys. Res. Lett., 35, L23806, 6 pp., doi:10.1029/2008GL035617, 2008.

Levin, Z. and Cotton, W. R. (Eds.): Aerosol Pollution Impact on Precipitation: A Scientific Review, Springer, Heidelberg and Karlsruhe, Germany, 386 pp., 2009.

Lynn, B., Khain, A., Dudhia, J., Rosenfeld, D., Pokrovsky, A., and Seifert, A: Spectral (bin) microphysics coupled with a mesoscale model (MM5), Part 2: Simulation of a CaPe rain event with squall line, Mon. Weather Rev., 133, 59-71, 1997.

Meyers, M. P. Walko, R. L., Harrington J. Y., and Cotton, W. R.: New Rams cloud microphyisics parameterization: Part II, The two-moment scheme, Atmos. Res., 45, 3-39, 2005.

Mitchell, D. L., Macke, A., and Liu, Y.: Modeling cirrus clouds, part II, Treatment of radiative properties, J. Atmos. Sci., 53, 2967-2988, 1996.

O’Dowd, C. D., Smith, M. E., Consterdine, I. E., and Lowe, J. A.: Marine aerosol, sea-salt, and the marine sulphur cycle: A short review, Atmos. Environ., 31, 73-80, 1997.

Pielke, R. A., Cotton, W. R., Walko, R. L., Tremback, C. J., Lyons, W. A., Grasso, L. D., Nicholls, M. E., Moran, M. D., Wesley, D. A., Lee, T. J., Copeland, J. H.: A comprehensive meteorological modeling system-RAMS, Meteorol. Atmos. Phys., 49, 6991, 1992.
Riemer, M., Montgomery, M. T., and Nicholls, M. E.: A new paradigm for intensity modification of tropical cyclones: thermodynamic impact of vertical wind shear on the inflow layer, Atmos. Chem. Phys., 10, 3163-3188, doi:10.5194/acp-10-31632010, 2010.

Ritter, B. and Geleyn, J. F.: A comprehensive radiation scheme for numerical weather prediction models with potential applications in climate simulations, Mon. Weather Rev., 120, 303-325, 1992.

Rosenfeld, D. and Khain, A: Anthropogenic aerosol invigorating hail, 2008, Proc. Int. Conf. on Clouds and Precipitation (Cancun, July 2008), 2008.

Rosenfeld, D., Khain, A., Lynn, B., and Woodley, W. L.: Simulation of hurricane response to suppression of warm rain by sub-micron aerosols, Atmos. Chem. Phys., 7, 3411-3424, doi:10.5194/acp7-3411-2007, 2007.

Saleeby, S. M. and Cotton, W. R.: A large-droplet model and prognostic number concentration of cloud droplets in the RAMS@CSU model. Part I: Module descriptions and Supercell test simulations, J. Appl. Meteorol., 43, 182-195, 2004.

Saleeby, S. M. and Cotton, W. R.: A Binned Approach to CloudDroplet Riming Implemented in a Bulk Microphysics Model, J. Appl. Meteorol., 47, 694-703, 2008.

Seifert, A. and Beheng, K.: A two-moment cloud microphysics parameterization for mixed-phase clouds, Part II: maritime versus continental deep convective storms, Meteorol. Atmos. Phys., 92 67-88, 2006.

Slingo, A. and Schreckner, M.: On shortwave properties of stratiform water clouds, Q. J. Roy. Meteor. Soc., 108, 407-426, 1982.

van den Heever, S. and Cotton, W. R.: Urban aerosol impacts on downwind convective storms, J. Appl. Met., 46, 828-850, 2007.

van den Heever, S. C., Carrió, G. G., Cotton, W. R., DeMott, P. J., and Prenni, A. J.: Impacts of nucleating aerosol on Florida convection, Part I: Mesoscale Simulations, J. Atmos. Sci., 63, 1752-1775, 2006.

Wang, Y.: An Explicit Simulation of Tropical Cyclones with a Triply Nested Movable Mesh Primitive Equation Model: TCM3, Part II: Model Refinements and Sensitivity to Cloud Microphysics Parameterization, Mon. Weather Rev., 130, 12, 30223036, 2002.

Wang, C.: A modeling study of the response of tropical deep convection to the increase of cloud condensational nuclei concentration: 1. Dynamics and microphysics, J. Geophys. Res., 110, D21211, doi:10.1029/2004JD005720, 2005.

Zhang, H., McFarquhar, G. M., Saleeby, S. M., and Cotton, W. R.: Impacts of Saharan dust as CCN on the evolution of an idealized tropical cyclone, Geophys. Res. Lett., 34, L14812, doi:10.1029/2007GL029876, 2005.

Zhang, H., McFarquhar, G. M., Cotton, W. R., and Deng, Y.: Direct and indirect impacts of Saharan dust acting as cloud condensation nuclei on tropical cyclone eyewall development, Geophys. Res. Lett., 36, L06802, doi:10.1029/2009GL037276, 2009. 